Article

\title{
Examining the Relationship between the Dimensions of the Climate-Change Competence (C3): Testing for Mediation and Moderation
}

\author{
Enzo Ferrari ${ }^{1, *(\mathbb{D})}$, Fernando Martínez-Abad ${ }^{2}$ (D) and Camilo Ruiz ${ }^{1, *(\mathbb{D})}$ \\ 1 EMC3 Research Group, Department of Math and Science Education, Universidad de Salamanca, \\ 37008 Salamanca, Spain \\ 2 Instituto Universitario de Ciencias de la Educación, Universidad de Salamanca, 37008 Salamanca, Spain; \\ fma@usal.es \\ * Correspondence: enzoferrari@usal.es (E.F.); camilo@usal.es (C.R.)
}

check for

updates

Citation: Ferrari, E.; Martínez-Abad,

F.; Ruiz, C. Examining the

Relationship between the Dimensions of the Climate-Change Competence

(C3): Testing for Mediation and

Moderation. Sustainability 2022, 14,

1895. https://doi.org/10.3390/

su14031895

Academic Editor: Grigorios

L. Kyriakopoulos

Received: 7 December 2021

Accepted: 31 January 2022

Published: 7 February 2022

Publisher's Note: MDPI stays neutral with regard to jurisdictional claims in published maps and institutional affiliations.

Copyright: (c) 2022 by the authors. Licensee MDPI, Basel, Switzerland. This article is an open access article distributed under the terms and conditions of the Creative Commons Attribution (CC BY) license (https:/ / creativecommons.org/licenses/by/ $4.0 /)$.

\begin{abstract}
The objective of this study is to analyze the positive relationship between different dimensions (knowledge, attitudes, and ability) of the Climate-Change Competence in the participants of a Massive Open Online Course called "Awareness and Training on Climate Change for Primary and Secondary Teachers". This study describes the use of this competence to introduce Climate Change into formal education and provides an example of how it can be used to design educational interventions to mobilize the students through education. We carried out a correlational research design based on mediation and moderation models using a process macro for questionnaires about the Climate-Change Competence. In this study, we used a sample of 530 people from Spain and Latin America $(52 \%$ female, mean age $=36.1$ years). The findings revealed that knowledge about Climate Change is a good predictor of ability and attitude. Furthermore, we predicted that the relationship between knowledge and ability would be mediated by attitude. Likewise, we hypothesized that attitude is a moderating dimension between knowledge and ability. The results supported our prediction and showed that attitude is a strong mediator in the relationship between knowledge and ability. However, the interaction between knowledge and attitude did not improve the ability to cope with Climate Change. The Climate-Change Competence is an efficient tool to introduce Climate Change into formal education. It can also be used to investigate, for the first time, the relationship between knowledge, ability, and attitude, which is essential to transform education into a necessary tool for mitigation and adaptation.
\end{abstract}

Keywords: Climate Change; Climate-Change Competence; knowledge; attitude; ability; ClimateChange education

\section{Introduction}

Climate Change (CC) is one of the greatest challenges facing humanity in the 21st century, threatening much of the biosphere and virtually all human activities [1]. A large number of studies have analyzed the devastating consequences produced by this phenomenon, which show the urgent need to act. Economically, losses resulting from heat stress are estimated to be several billion annually [2]. In addition, the capacity to produce goods and products will be reduced; it has been shown that CC can reduce the working capacity to $90 \%$ in the hottest months [3]. The consequences are not only economical, but they also affect society as a multiplicative threat. CC increases violence, general health and psychological disorders, as well as reduces the sense of well-being [4]. Its impact is also extended into the animal kingdom by reducing animal feeding and growth rates [5] and reducing livestock reproduction rates [6]. These are only a few examples of the complex and broad consequences of CC for all habitants on Earth. These complex interactions of the climate with other socio-environmental problems create a planetary emergency which 
needs to be addressed with urgency [7,8]. Given these consequences, this phenomenon needs to be addressed with coordinated strategies for adaptation and mitigation at all levels, from local to global organizations. Education, in particular, should play a fundamental role in improving the resilience of the communities and helping to improve the mitigation and adaptation strategies. A considerable consensus exists [9] on the need to consolidate education as a primary tool to mobilize society in the face of this global crisis [10].

The role of education has been described explicitly in several international treaties and laws. For example, Education for Sustainable Development (ESD) introduced by UNESCO is a comprehensive proposal to create a new generation of citizens with the knowledge, skills, and attitudes to create a more sustainable world [11]. The Sustainable Development Goals (SDGs) introduced by the UN [12] are another example of how education needs to be implemented to reduce and prevent the worst scenarios of CC. SDG 13, which refers to climate action, has three targets and aims. In particular, target 13.3 explains that education needs to be improved in order to reduce the impact of Climate Change through mitigation and adaptation. The Paris treaty on CC also describes the importance of education and the need to establish an emergency curriculum about CC [13].

The scientific literature has also discussed in great lengths the need to incorporate CC into formal education. Authors such as Mochizuki and Bryan [14] are more specific and raised the issue of Climate-Change education, which is needed in order to provide people with transversal skills and abilities that enrich their cognitive and affective domains to cope with this phenomenon. Other authors say that this task should be an interdisciplinary approach that encompasses scientific, socio-economic aspects and possible solutions [15] to educate regarding Climate Change [16]. Critical reviews have been dedicated to this matter wherein they compile the arguments in favor of new Climate-Change curricula and competences [16-21].

Although CC education is recognized as a fundamental tool to tackle CC by the general public, the institutions, and the experts, there is no clear strategy for implementing it effectively into the education system. The educational response to CC has been very uneven, but recent publications demonstrate a range of proposals leading to different levels of enactment and uptake [22]. Some local authorities and some states have already presented proposals for the introduction of Climate Change in schools, but the efforts are still isolated.

We have proposed a new comprehensive alternative to achieve this goal in the form of a Climate-Change Competence (C3) [23]. This construct joins two major branches: (a) Institutional Climate-Change response, which includes mitigation and adaptation, and (b) multidisciplinary education leading to action. The Competence has three principal dimensions:

- Knowledge. In order to understand the nature of Climate Change, it is essential to understand the basic science of this phenomenon, as well as the causes and consequences, together with the magnitude of its impact and comprehension of the multidimensional challenge.

- Abilities. An extensive set of abilities ranging from daily and local to global and complex actions must combat CC. These abilities will improve the resilience of the communities and enhance their capacity for adaptation and mitigation.

- Attitudes. These develop an awareness of the problem, which is necessary in order to act with urgency on this global issue. Present and future citizens need to coherently and responsibly mobilize with growing autonomy, judgment, and personal responsibility.

The structure of the $\mathrm{C} 3$ is optimal as it allows us to organize the institutional references and the contributions in the scientific literature into dimensions that are well recognized by the education community. Similar competences regarding education about sustainable development have been introduced but with the focus outside formal education. Although, among these proposals are the action competence [24], the sustainability competence [25], and other more specific competences such as the environmental-health competence [26] 
and the environment competence [27]; in all cases, the adaptation and mitigation of Climate Change are introduced marginally. Additionally, the focus is usually only a descriptive analysis of the dimensions [28] and not an in-depth study of the relationships between competences or their dimensions.

In the framework of the $\mathrm{C} 3$, scientific knowledge is necessary to understand the complex nature of the phenomenon, the interconnections between different parts of the climate systems and how human civilization depends on climate stability and a rich biodiversity. A basic understanding of the future scenarios and the impact of human activity on the environment is also essential to understand the problem and relate it to mitigation and adaptation efforts. But knowledge alone is not enough: values, awareness, and attitudes are needed to understand the urgency of the situation and the need to act in a coherent and informed way. Finally, and perhaps most importantly, knowledge and attitudes should promote action, help to create habits, promote skills and improve the mitigation and adaptation strategies at the individual [29], local and global levels.

This last part is the most important as the overall goal of including CC in education is to improve resilience and the abilities of mitigation and adaptation. Research into how different dimensions interact within the competence is vital to understand the most effective strategies for implementing the $\mathrm{C} 3$ in schools.

The dimensions of the Competence need to work together within the education system to improve our response to this phenomenon, the Competence is meant to be present through all the curriculum and in all disciplines and the goal is to mobilize the future citizens around this problem. Therefore, we need to understand the structure of the Competence and the interaction between the different dimensions to design and implement effective educational strategies to achieve the Competence goals.

Additionally, understanding the relationship between different dimensions of the Competence could help us to distinguish different profiles of students, representing different but equivalent paths of acquiring the C3. For example, we can think about the profile of a virtuous person or student who has high knowledge, high attitudes, and acts accordingly with good abilities, thereby maximizing their personal impact. While this is efficient and good, some other profiles are also needed and desired; another less virtuous but equally applicable profile is a person with basic knowledge and attitudes but high skills and efficiency in implementing mitigation and adaptation practices.

The importance of studying the relationship between dimensions of competences has been recognized in the literature. Several environmental researchers and educators have focused in recent decades on the relationship between knowledge, attitudes, and behaviors, or abilities in the framework of CC. Researchers in this field explain that to act against CC, people must understand the science of this phenomenon [30]. Therefore, the knowledge dimension has been considered an essential factor to improve the environment's ability [31].

Similarly, other researchers are more specific and explained that to acquire proenvironmental behaviors, the knowledge dimension needs to be integrated with three elements that include understanding (a) the importance of the human actions on natural systems, (b) the problems arising from the interactions between social systems and natural systems and (c) the recognition and evaluation of the different actions for mitigating the environmental crisis through pro-environmental actions [32]. Other studies about the relationship between these dimensions have revealed a strong positive relationship between environmental knowledge and environmental attitudes [33,34]. Similarly, relationships between attitudes and abilities can occur. Attitudes are responsible for generating feelings and concern for specific environmental issues, and these feelings can cause action to solve environmental problems leading to abilities regarding these issues. For example, a study has shown a positive relationship between individuals' attitudes and environmental behaviors [35], where the attitudes directly and indirectly affected the pro-environmental behaviors. Another study performed on adolescents with pro-environmental attitudes and knowledge demonstrated high pro-environmental behaviors [36]. However, to strengthen the relationship between abilities and attitudes, it is necessary to know the science of this 
phenomenon. To give an illustration, a study in Italy showed that the scientific knowledge of CC focused on the physics and chemistry of this phenomenon, as well as its causes and consequences, had a positive impact on the people's daily activities, thereby helping to address Climate-Change mitigation [37].

These studies show the importance of the interaction between different dimensions of competences and how all three of them are necessary and complementary, but a closer look at these interactions in the case of the Climate-Change Competence (C3) can help us to define effective educational strategies. Therefore, in this paper, we will analyze the mediation and moderation between the knowledge, ability, and attitude of the C3. This is the main novelty of the study.

Our two main research questions are:

RQ1: Can attitudes towards CC mediate the correlation between knowledge and ability towards CC in students?

RQ2: Can attitudes towards CC strengthen or moderate the relationship between knowledge and abilities?

These questions are essential to reveal which of the three dimensions are necessary to produce action and behaviors in front of the CC crisis.

\section{Methods}

To study the interactions between the dimensions of the $\mathrm{C} 3$, we designed and validated an instrument that consisted of a questionnaire with 36 items that can be found in Appendix A. The questionnaire was implemented to assess the different dimensions and sub-dimensions of the $\mathrm{C} 3$. The questionnaire was applied to a group of students who took the MOOC "Awareness and Training on Climate Change for Primary and Secondary Teachers" in April 2019. The MOOC was distributed through the MiriadaX platform in Spanish-speaking countries. The MOOC was designed and produced by our research group at the Salamanca University. The course answers four basic questions around CC.

- What is CC?

- What are the causes of CC?

- What are the consequences of CC?

- What can we do about it?

The MOOC focuses on the basic science of CC, presenting the scientific evidence of the physical and chemical mechanisms that produce the increase in global temperatures and all the related effects on the different climate systems and their anthropogenic origin. The MOOC contents were structured in seven consecutive modules that also included a discussion forum where participants could interact with each other. Moreover, the participants had to attend a predetermined program. Furthermore, they were evaluated with a small test at the end of each module and in peer-to-peer activities [38].

The objective of the methodology, in this case, was to measure the influence of each of the dimensions on the other dimensions by mediation and moderation analysis.

\subsection{Participants}

The sample consisted of 530 ( $52 \%$ female and $48 \%$ male) participants enrolled at the MOOC called "Awareness and Training on Climate Change for Primary and Secondary Teachers", who responded voluntarily and anonymously to an online survey in Spanish.

They accepted to participate voluntarily in our study, providing us with their consent. The mean age of participants was $36.1(S D=13.6)$, they came from 24 countries, mainly from Latin America (58.9\%) and Spain (38.1\%), and to a lesser extent from Italy, Portugal, and Africa. Considering the occupation variable, $46.5 \%$ were teachers, $26.4 \%$ were students, and the rest of the sample was from other occupations.

\subsection{Instrument}

The questionnaire has three sections devoted to the three dimensions of competence. Each of the dimensions has several items that can be used to analyze the interaction between 
each of the dimensions within the Competence. The dimensions are, in turn, divided into sub-dimensions which take into account specific aspects of the Competence. Figure 1 summarizes the elements of the C3. The McDonald omega coefficient [39] was used to estimate reliability (it relates to the correlation between observed and true scores) because of the better stability of its calculation with non-continuous data to avoid underestimation [40].

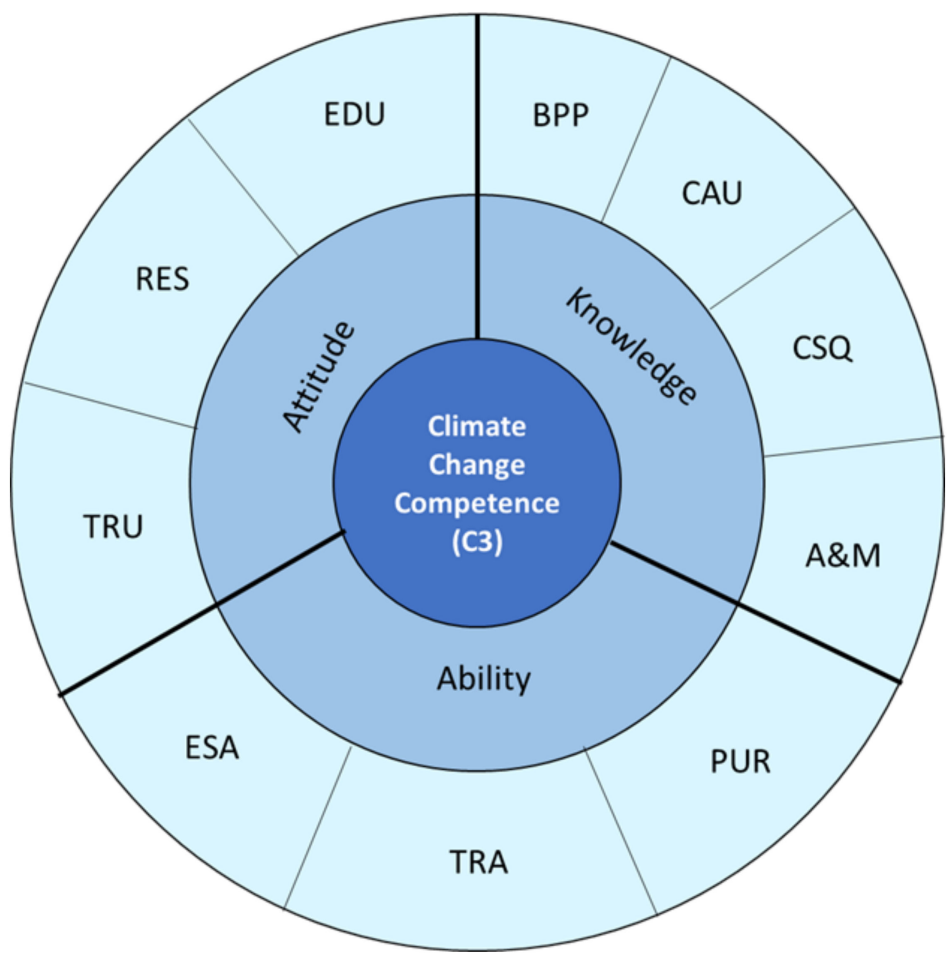

Figure 1. Conceptual representation of the Climate-Change Competence (C3). BPP: biophysical processes; CAU: causes; CSC: consequences; A\&M: adaptation and mitigation; PUR: purchases; TRA: transport; ESA: energy savings; TRU: trust per agent; RES: responsibility; EDU: educational interest.

\subsubsection{Knowledge Dimension}

This dimension includes 14 items (Appendix A, Table A1), measured on a 4-point scale of scientific knowledge about the physics and chemistry of Climate Change. The categories to answer these items were: "False", "Somewhat false", "Somewhat true" and "True". The sub-dimensions of knowledge are (a) biophysical processes (BPP), (b) causes (CAU), (c) consequences (CSQ), and (d) adaptation and mitigation (A\&M). These sub-dimensions were taken from such previous studies as the United States Global Change Research Program [41] and Resclima [16,42-44] proposals. A complete definition and justification of these sub-dimensions can be found in Ferrari et al. (under submission). We evaluated the overall fit of the models of scales using the statistics proposed by Schreiber [45]. Chi-square $\left(\chi^{2}\right)$ : Because it is susceptible to sample size, the additional normed chi-square $\left(\chi^{2} / \mathrm{df}\right)$ was used, with values $<3$ indicating an acceptable fit between the hypothetical model and the sample data. Comparative Fit Index (CFI): Values greater than 0.95 may be interpreted as an acceptable fit. Tucker-Lewis Index (TLI): Values greater than 0.90 are usually interpreted as indicating an acceptable fit. Root Mean Square Error of Approximation (RMSEA): Values less than 0.08 indicate an excellent fit. Standardized Root Mean Square Residual (SRMR): Values small, i.e., close to 0, indicate a perfect fit. Confirmatory Factor Analysis (CFA) [45] showed that the four-factor model obtained the best fit $\left(\chi^{2}(71, n=530)=139.65, p<0.001\right.$, $\chi^{2} / \mathrm{gl}=1.96$, comparative Fit Index $(\mathrm{CFI})=0.950$, Tucker-Lewis Index $(\mathrm{TLI})=0.936$, Root mean square error of approximation $($ RMSEA $)=0.044$, and standardized root mean square residual $(\mathrm{SRMR})=0.058)$. 


\subsubsection{Ability Dimension}

This dimension includes 9 items (Appendix A, Table A2), which were measured on a 4-point scale based on the frequency with which the participants carried out a series of activities related to Climate-Change mitigation. The categories to answer these items were: "Never", "Occasionally", "Frequently" and "Always". The sub-dimensions of ability are (a) purchases (PUR), (b) transport (TRA), and (c) energy savings (ESA), which were taken from previous studies [46-48]. The results of the goodness-of-fit test showed that the three-factor model obtained the best fit $\left(\chi^{2}(24, n=530)=40.15, p=0.021, \chi^{2} / \mathrm{gl}=1.67, \mathrm{CFI}=0.988\right.$, $\mathrm{TLI}=0.982$, RMSEA $=0.036$, and $\mathrm{SRMR}=0.046)$.

\subsubsection{Attitude Dimension}

This dimension includes 13 items (Appendix A, Table A3), which were measured on a 4-point scale that analyzed the trust of information on CC explained by the different agents as well as the responsibility of everybody to act against this phenomenon and how education can help to develop a better citizen awareness by creating a Climate-Change Competence. The sub-dimensions of ability are (a) trust per agent (TRU), (b) responsibility (RES), both with the answer options in "None", "Little", "Enough" and "Much" and (c) contribution by education (EDU) in which the degree of agreement was expressed as "None", "Little", "Enough" and "Totally". Here we referenced a literature review [49-53] as well. The CFA showed that the three-factor model was the model with the best fit $\left(\chi^{2}(62\right.$, $n=530)=73.95, p=0.142, \chi^{2} / \mathrm{gl}=1.19, \mathrm{CFI}=0.994, \mathrm{TLI}=0.993, \mathrm{RMSEA}=0.019$, and SRMR $=0.063$ ).

For the following analysis, the predictor variable was the knowledge about CC, the criterion variable was the ability dimension, and the attitude was a mediator and moderator between knowledge and ability.

\subsection{Design}

We applied a correlational research design based on mediation (a hypothetical causal chain where one variable $X$ affects a second variable $M$ and, in turn, that variable affects a third variable $Y$ ) and moderation (also allows for the testing of the influence of a third variable $W$ on the relationship between variables $X$ and $Y$ ) [54] through survey studies [55] on the participants of the second edition of the MOOC "Awareness and Training on Climate Change for Primary and Secondary Teachers" during April 2019.

We developed ex-post-facto research starting with the MOOC. Thereby, we did not directly modify the object of study, but we tried to locate the existing relationships between the analyzed variables. For this purpose, we carried out two mean analyses. First, we assessed whether attitudes about CC mediated the correlation between knowledge and ability towards CC in students. Figure 2 conceptually presents this analysis.

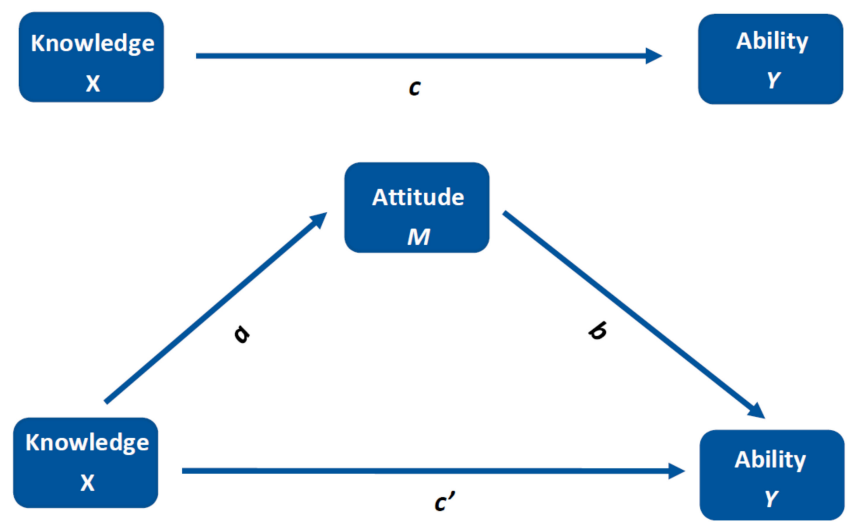

Figure 2. The unmediated path between knowledge $(X)$ and ability $(Y)$ is presented above $(c)$. Below, attitude $(M)$ is added, resulting in a simple mediation diagram. The indirect effect is $a^{*} b$. 
Second, we analyzed whether attitudes strengthened or moderated the relationship between student knowledge and abilities. Figure 3 conceptually presents this analysis.

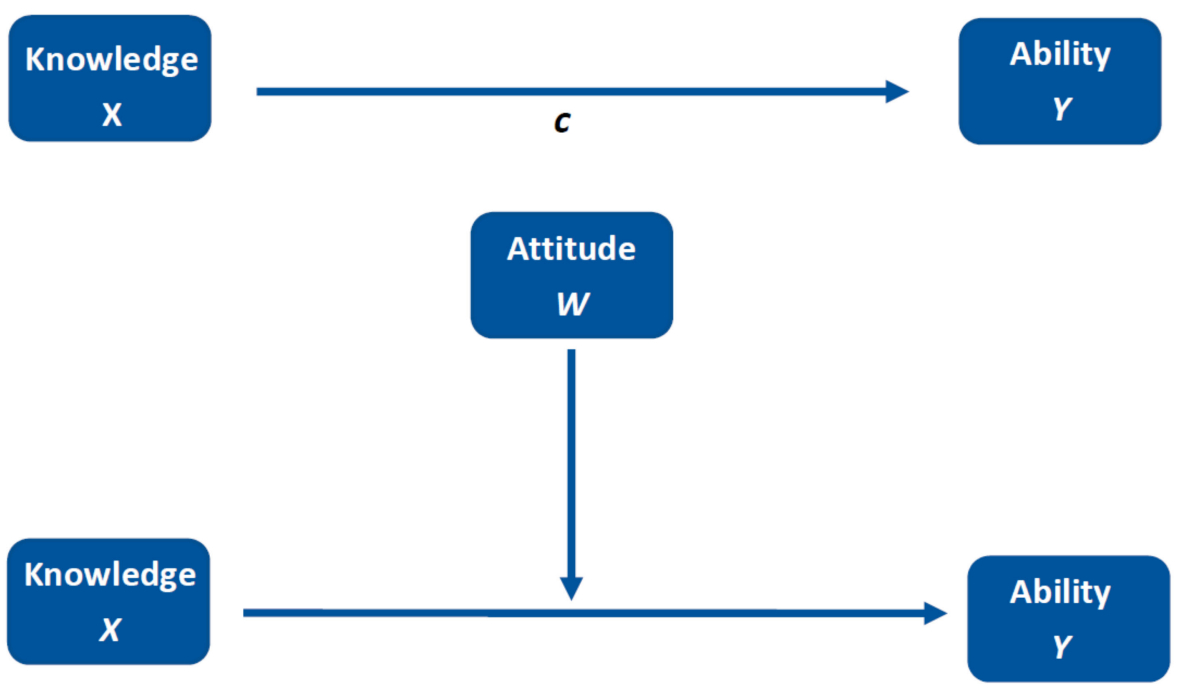

Figure 3. The moderated path between knowledge $(X)$ and ability $(Y)$ by attitude $(W)$. The interaction effect is $X^{*} W$.

\subsection{Data Analysis}

The aim of this study was to analyze the relationship between the dimensions of Climate-Change Competence (C3). Hence, a three-step data-analysis procedure was undertaken. In the first step, a descriptive exploration of the data was applied (mean, standard deviation, McDonald coefficient, and correlations among the dimensions of C3). According to Cohen [56], the effect size of correlations can be small (0.10 to 0.29$)$, medium (0.30 to 0.49) and large (equal to or greater than 0.50). In the second step, we verified that we could apply Linear Regression Analysis, for which we made the following assumptions: that there was a linear relationship between variables (checked by scatterplots of pairs of variables), that errors were normally distributed (checked by normal probability plot), the homoscedasticity of errors (checked by residual by predicted plot) and the independence of the observations (verified by the Durwin-Watson test). We checked for the absence of multicollinearity using variance-inflation-factor (VIF) values in a Multiple Linear Regression as well. In the third step, mediation and moderation analysis between different dimensions of the Competence were run. Bootstrapping with 10,000 replications was run to determine the significance of the indirect effect. To determine the effect size of the mediating analysis, we used proportion mediation $\left(P_{M}\right)$. Furthermore, we computed the kappa squared $\kappa^{2}$ [57], the value of which is interpreted in the same light as the coefficient of determination $\left(R^{2}\right)$, for which Cohen [56] determined small, medium, and large effect sizes are stated as 0.01, 0.09, and 0.25 , respectively. In the moderated analysis, the R-squared change $\left(\Delta R^{2}\right)$ was used as the effect size, where values as $0.02,0.13$, and 0.26 were interpreted as small, moderate, and large, respectively. Correlations and a linear regression analysis were performed with Software Jamovi 1.6.3.

\section{Results}

\subsection{Descriptive Statistics}

Descriptive statistics, internal consistencies, and the correlations among the dimensions of the C3 are shown in Table 1. They reflect the overall performance of the subjects in the sample with relation to the $C 3$; we evaluated this performance over the three dimensions. The mean response to the ability dimension was 3.06 (4 is the maximum), indicating a medium level. The attitude dimension was higher (3.68), indicating a high level. The internal consistency of the dimensions was adequate $(>0.70)$ 
Table 1. Descriptive statistics, McDonald omega and intercorrelations.

\begin{tabular}{cccccc}
\hline Dimensions & $\boldsymbol{M}$ & $\boldsymbol{S D}$ & $\boldsymbol{\omega}$ & Knowledge & Ability \\
\hline Knowledge & 3.10 & 0.837 & 0.730 & & \\
Ability & 3.06 & 0.654 & 0.778 & $0.300^{* *}$ & \\
Attitude & 3.68 & 0.447 & 0.886 & $0.430^{* *}$ & $0.394^{* *}$ \\
\hline
\end{tabular}

M: mean; SD: standard deviation; $\omega$ : McDonald omega; ${ }^{* *}: p<0.001$.

\subsection{Attitude Mediating Knowledge-Ability Relationship}

To answer our first research question, a statistics analysis was conducted in order to examine the impact of the knowledge dimension on the ability dimension, mediated by the attitude dimension. It was hypothesized that knowledge about $\mathrm{CC}$ would positively predict ability. Additionally, it was hypothesized that attitude would mediate this relationship. A series of regression analyses were conducted in order to test these hypotheses. The first and more important result shows that knowledge about CC positively influences ability $(B=0.358, z=7.01, p<0.001)$. This is an important issue which highlights the great degree of correlation between the dimensions, which we should consider as we analyze the C3. The positive effect between knowledge and ability can also be enhanced by the attitude dimension. Analyzing the indirect effects, our results reveal that attitude significantly mediates the relationship between knowledge and ability, $a b=0.164, z=5.88, p<0.001$ ( $95 \%$ CI, 0.109 to 0.219 ). This effect had a $k^{2}=0.129$.

The knowledge dimension positively affects attitude $(B=0.396, z=10.61, p<0.001)$ and the attitude dimension, in turn, positively affects the ability dimension $(B=0.414$, $z=7.07, p<0.001)$. Nevertheless, the results suggest that even after accounting for the mediating role of the attitude dimension, the knowledge dimension still has a positive impact on ability $(B=0.194, z=3.60, p<0.001)$. All of these results are summarized in Figure 4 .

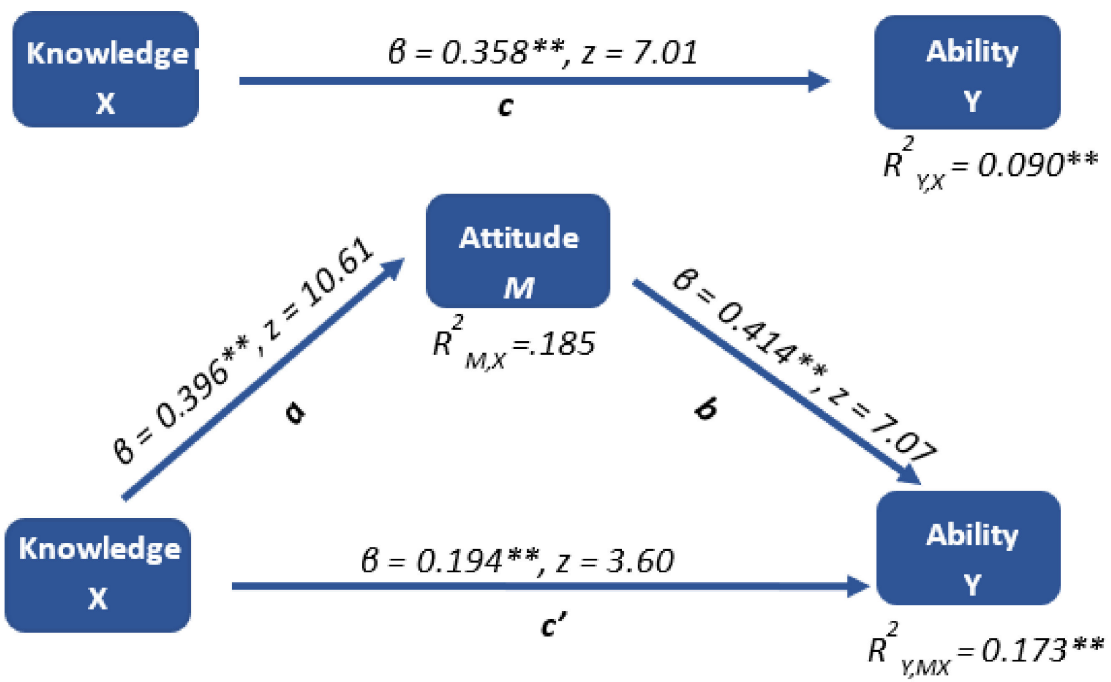

Figure 4. The unmediated (above) and mediated models (below). ${ }^{* *}: p<0.001$, Regression weights $a$, $b, c$, and $c^{\prime}$ are illustrated in Figure 2. B: coefficient; $z$ : Z-Test; $R^{2} Y, X$ : variance in $Y$ explained by $X$; $R^{2}{ }_{M, X}$ : variance in $M$ explained by $X$; and $R^{2}{ }_{Y, M X}$ : variance in $Y$ explained by $X$ and $M ;$ Knowledge is the independent variable $(X)$; Attitude is the mediator $(M)$; and Ability is the outcome $(Y)$; $\rightarrow$ : affects.

The mediating variable attitude accounts for $45.8 \%\left(P_{M}\right)$, representing almost the middle of the total effect. More details are shown in Table 2. These findings provide some evidence that people who have scientific knowledge about the physics and chemistry of CC are more likely to take actions related to CC mitigation because they tend to possess a higher awareness of being able to act against CC with growing autonomy, judgment, and personal responsibility. The implications of these results will be discussed below. 
Table 2. Regression results for the mediation of the effect of knowledge on ability by attitude.

\begin{tabular}{cccccc}
\hline & & & & CI & CI \\
\hline Model & $B$ & $S E$ & $z$ & (lower) & (upper) \\
\hline Model without mediator & & & & & \\
Intercept & $2.00^{* *}$ & 0.167 & 11.96 & 1.67 & 2.33 \\
Knowledge $\rightarrow$ Ability $(c)$ & $0.358^{* *}$ & 0.051 & 7.00 & 0.216 & 0.385 \\
$R^{2} Y, X$ & $0.090^{* *}$ & & & & \\
Model with mediator & & & & & \\
Intercept & $2.345^{* *}$ & 0.122 & 19.17 & 2.10 & 2.59 \\
Knowledge $\rightarrow$ Attitude $(a)$ & $0.396^{* *}$ & 0.037 & 10.61 & 0.323 & 0.470 \\
Attitude $\rightarrow$ Ability $(b)$ & $0.414^{* *}$ & 0.058 & 7.07 & 0.299 & 0.528 \\
Knowledge $\rightarrow$ Ability $\left(c^{\prime}\right)$ & $0.194^{* *}$ & 0.054 & 3.60 & 0.088 & 0.300 \\
$\quad$ Indirect effect $(a b)$ & $0.164^{* *}$ & 0.028 & 5.88 & 0.109 & 0.219 \\
$R^{2}{ }_{M, X}$ & $0.185^{* *}$ & & & & \\
$R^{2}{ }_{Y, M X}^{* *}$ & $0.173^{* *}$ & & & & \\
\hline
\end{tabular}

***: $p<0.001, B$ : coefficient; SE: Estimated error; $z$ : Z-Test; Regression weights $a, b, c$, and $c^{\prime}$ are illustrated in Figure 2. $R^{2} \gamma_{Y}$ : variance in $Y$ explained by $X ; R^{2}{ }_{M X}$ : variance in $M$ explained by $X$; and $R^{2}{ }_{Y, M X}$ : variance in $Y$ explained by $X$ and $M$; Knowledge is the independent variable $(X)$; Attitude is the mediator $(M)$; and Ability is the outcome $(Y)$; $\mathrm{CI}$ (lower): lower bound of a 95\% confidence interval; $\mathrm{CI}$ (upper): upper bound; $\rightarrow$ : affects.

\subsection{Attitude Moderating Knowledge-Ability Relationship}

To answer our second research question, we analyzed whether the attitude dimension could moderate the relationship between knowledge and ability. While in the first research question the focus was on how the ability dimension could grow, next we analyzed if attitude could strengthen the relationship between knowledge and ability. As we could see in the first research question, the knowledge dimension is a positive predictor of ability. Similarly, in this model, attitude is helpful as an individual positive predictor of ability $(B=0.412, z=7.80, p<0.001)$. We are more interested in this case due to the relation between knowledge and attitude (Figure 5).

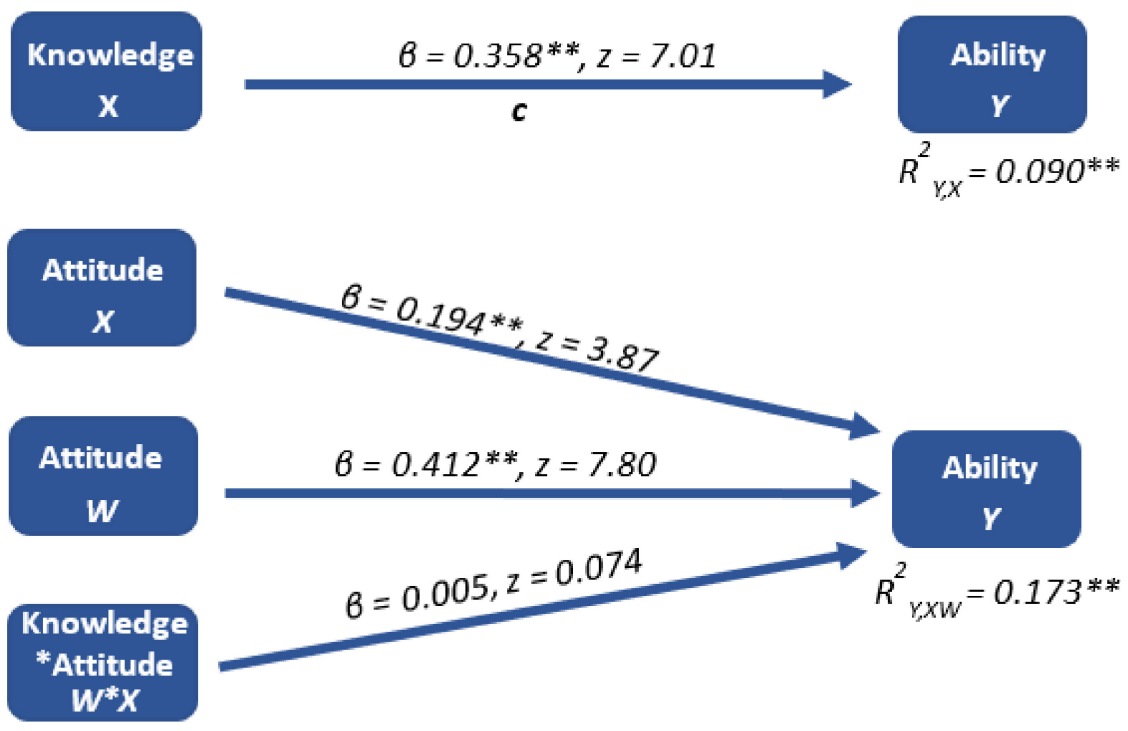

Figure 5. The unmoderated (above) and moderated models (below). ${ }^{* *}: p<0.001$; $B$ : coefficient; $z$ : Z-Test; $R^{2}{ }_{Y, X}$ : variance in $Y$ explained by $X$; and $R^{2}{ }_{Y, X W}$ : variance in $Y$ explained by $X, W$ and $X^{*} W$; Knowledge is the independent variable $(X)$; Attitude is the moderator $(W)$; Interaction $\left(X^{*} W\right)$ and Ability is the outcome (Y); CI (lower): lower bound of a $95 \%$ confidence interval; $\mathrm{CI}$ (upper): upper bound.

However, the results show that attitude does not significantly moderate the relationship between knowledge and ability $(B=-0.005, z=-0.074, p=0.961)$. More details are 
shown in Table 3. While both dimensions, knowledge and attitude, are great predictors of ability, there is no interaction effect between those variables and ability.

Table 3. Summary of moderated-regression-analysis predicting ability.

\begin{tabular}{cccccc}
\hline & & & & CI & CI \\
\hline Model & $\boldsymbol{B}$ & $\boldsymbol{S E}$ & $\boldsymbol{z}$ & (lower) & (upper) \\
\hline Model without moderator & & & & & \\
Intercept & $2.34^{* *}$ & 0.122 & 19.17 & 2.10 & 2.59 \\
Knowledge $\rightarrow$ Ability $(c)$ & $0.358^{* *}$ & 0.051 & 7.00 & 0.216 & 0.385 \\
$R^{2} Y, X$ & $0.090^{* *}$ & & & & \\
Model with moderator & & & & & \\
Intercept & 0.977 & 0.805 & 1.21 & -0.681 & 2.56 \\
Knowledge $(X)$ & $0.194^{* *}$ & 0.005 & 3.87 & 0.096 & 0.292 \\
Attitude $(W)$ & $0.412^{* *}$ & 0.005 & 7.80 & 0.309 & 0.516 \\
$X^{*} W$ & -0.005 & 0.007 & -0.074 & -0.142 & -0.131 \\
$R^{2} Y, X W$ & $0.173^{* *}$ & & & & \\
\hline
\end{tabular}

**: $p<0.001, B$ : coefficient; $S E$ : Estimated error; $z$ : Z-Test; Regression weight $x$ is illustrated in Figure 3. $R^{2} \gamma, X$ : variance in $Y$ explained by $X$; and $R^{2} Y, X W$ : variance in $Y$ explained by $X, W$ and $X^{*} W$; Knowledge is the independent variable $(X)$; Attitude is the moderator $(W)$; Interaction $\left(X^{*} W\right)$ and Ability is the outcome $(Y)$; $C I$ (lower): lower bound of a $95 \%$ confidence interval; $\mathrm{CI}$ (upper): upper bound.

We applied the Johson-Neyman technique to confirm that the moderator variable (attitudes) does not produce a significant effect on the correlation between knowledge and abilities. This is explained in Figure 6, where the effect of the correlation between both variables (Y-axis) does not change across the different values of attitude (X-axis).

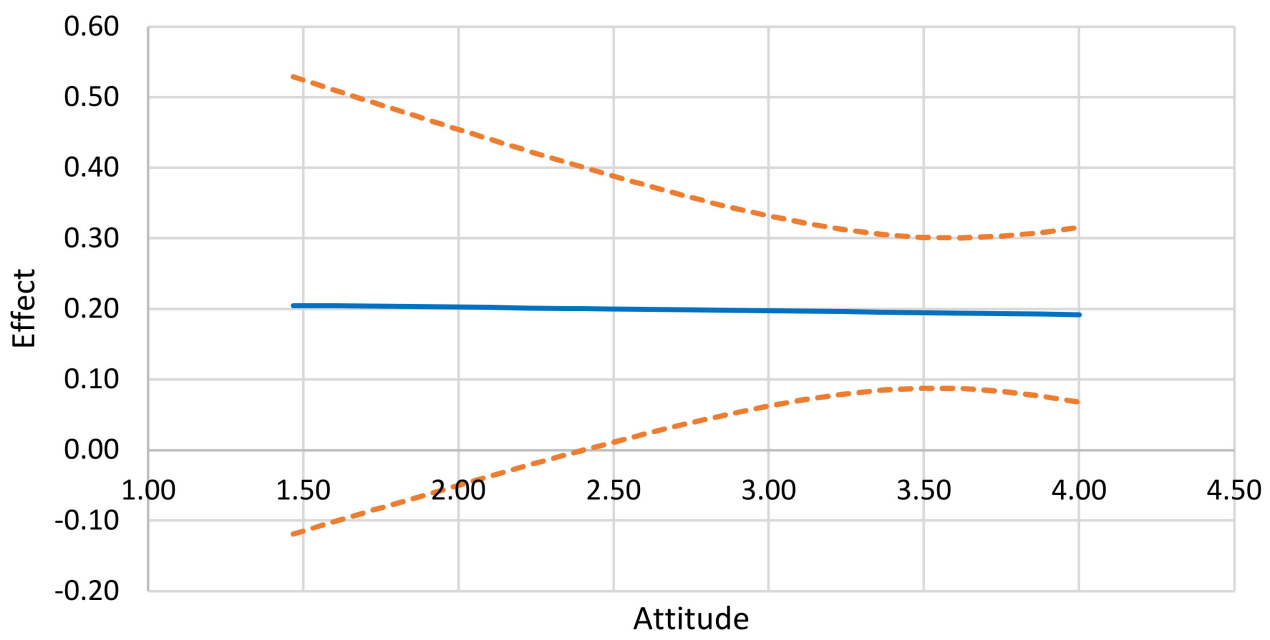

Figure 6. At a 95\% confidence level, the effect of knowledge on ability is not significant anywhere in the range of measurements of attitude.

\section{Discussion}

Our analyses are based on the Climate-Change Competence (C3) proposed by FerrariLagos et al. [58] and Fuertes et al. [23] that defines a structure with three dimensions: learning to know (scientific knowledge as the physics and chemistry of CC, causes, and consequences), learning to do (CC adaptation and mitigation) and learning to be (awareness to be able to act with growing autonomy, judgment, and personal responsibility). Our correlation analysis revealed that there is a medium correlation between the dimensions of C3. Recent environmental research has reported moderate correlations between knowledge, attitude, and ability [59], strengthening our findings. The primary objective of this paper was to analyze the relationship between the dimensions of Climate-Change Competence (C3). To fulfill this overarching goal, the analyses focused on answering two main ques- 
tions: whether the attitude dimension mediates the correlation between knowledge and abilities, and whether the attitude dimension can moderate and ultimately strengthen the relationship between knowledge and ability.

Our first research question was targeted at determining if attitudes about CC have a potential role (mediator) in the relationship between knowledge and ability regarding CC. In the mediation model that we tested there was a medium effect size, which is significant. The findings presented here provide three key facts about the knowledge dimension in the C3. First, that an increase in the knowledge dimension implies an improvement in attitudes. This result is in line with other studies, such as that of Masud et al. [60] which also found that knowledge of CC has a positive and significant impact on attitudes to CC. Similarly, Liu et al. [61] reported that environmental knowledge has a significant positive effect on environmental attitudes. Another study found that general and specific knowledge about carbon is linked to widespread environmental attitudes [62]. Second, our results show that attitude mediates the effect of CC knowledge on the improvement of people's abilities. This finding is consistent with earlier studies [60,63], which reported an indirect effect of knowledge, awareness, and risk perception on abilities through environmental attitudes, which is significant. Likewise, Waris \& Hameed [64] found that knowledge of ecolabels and altruism have a positive influence on attitudes toward energy-efficient-purchase intention. Third, there is a direct effect of knowledge of CC on the ability to respond to this phenomenon. This result is congruent with research conducted by Busch et al. [65] which showed that causes and consequences of $\mathrm{CC}$ were a direct predictor of behavior.

Our findings explain that attitudes about Climate Change yield an indirect effect on the relationship between knowledge and ability. These results could be helpful to improve the activities of mitigation through scientific knowledge of the physics and chemistry of $\mathrm{CC}$ and the creation of the awareness to act against CC with growing autonomy, judgment, and personal responsibility.

Our second research question was targeted to determine if attitudes strengthen the relationship between knowledge and abilities. To answer this question, we applied an analysis of moderation, wherein attitude worked as a moderating variable. The findings, again, pointed to three important facts. First, that knowledge of CC is a predictor of the ability to address it. According to Levine \& Strube [66] and Kuhlemeier et al. [67], knowledge increases the ability to be more responsible with the environment. Second, there is a positive significant relationship between knowledge of CC and attitudes toward this phenomenon. Our result is supported by Higde et al. [68]; they found that values and attitudes around CC are essential determinants of abilities. Third, surprisingly, our findings suggest that attitudes do not moderate the relationship between knowledge and abilities. This result implies that the relationship between knowledge and ability remains unchanged, regardless of the level of attitudes of the person. In contrast with the studies that used the dimensions of competences as moderating variables, which are a majority of those referenced, we used knowledge as a moderating variable in the relationship between attitudes and abilities [69-72]. Therefore, we found no studies to support our results, and more research is needed in this field. However, one study showed that environmental awareness is a moderating variable between attitudes and behaviors [73].

\section{Conclusions}

Along with the observations from the references above, our results confirm that the correlations between the dimensions of the Climate-Change Competence (C3) are important. We studied two essential questions about the structure and relationships between the dimensions of C3. We have shown that knowledge about CC science is an essential predictor of attitude and ability in the Competence. Moreover, attitude is a strong mediator in the relationship between knowledge and ability. This means that attitudes provide an indirect effect that enhances ability. However, attitudes do not moderate the relationship between knowledge and ability, possibly because these already exhibit a moderate correlation, leading this correlation to remain unchanged at all levels of attitudes. 
These results can help to design better courses, curricula or educational programs wherein a good balance between the different dimensions of the $C 3$ needs to be achieved in order to trigger action for better mitigation or adaptation strategies. Although our sample was limited to Latin America and Spain, it provides important insight into the mechanism behind the $\mathrm{C} 3$.

This research opens the door to further studies in demographically diverse samples to discover other potential moderators and mediators of the relationship between the dimensions of the C3 or to use other types of methodology such as longitudinal studies and pre/post-experimental studies to gain a richer understanding of the causal relations between the dimensions of the C3. Furthermore, in view of the limited number of studies where attitudes work as moderating variables between knowledge and ability regarding CC, more studies addressing these relationships are needed in order to support or contradict our results.

Author Contributions: Conceptualization, C.R. and F.M.-A.; methodology, F.M.-A.; software, E.F.; validation, E.F.; formal analysis, E.F.; investigation, E.F.; resources, C.R.; data curation, E.F.; writingoriginal draft preparation, E.F.; writing-review and editing, C.R. and F.M.-A.; visualization, E.F.; supervision, F.M.-A. and C.R.; project administration, C.R.; funding acquisition, C.R. All authors have read and agreed to the published version of the manuscript.

Funding: This research was funded by Ministerio de Ciencia e Innovación MCIN, grant number PID2020-114358RB-I00" FEDER “Una manera de hacer Europa”.

Institutional Review Board Statement: Ethical review and approval were waived for this study due to compliance with the Data protection legislation.

Informed Consent Statement: Informed consent was obtained from all subjects involved in the study.

Data Availability Statement: The data presented in this study are available upon reasonable request to the authors.

Acknowledgments: We would like to acknowledge all members of the EMC3 research group at the Salamanca University for valuable discussions and the design, implementation and production of the MOOC "Awareness and training on Climate Change for Primary and Secondary teachers".

Conflicts of Interest: The authors declare no conflict of interest.

\section{Appendix A}

Table A1. Knowledge Dimension of Climate Competence. Instructions: Below are a series of statements about Climate-Change content. If you are entirely sure of your answer, answer 'Completely True' or 'Completely False'. You can answer 'Probably True' or 'Probably False' if in doubt.

\begin{tabular}{|c|c|c|}
\hline No. & Dimension & Item \\
\hline 1 & \multirow{3}{*}{$\mathrm{BPP}$} & The Greenhouse Effect is a natural phenomenon. \\
\hline 2 & & $\mathrm{CO}_{3}$ is a natural component of the atmosphere. \\
\hline 3 & & Without the Greenhouse Effect, there would be no life as we know it. \\
\hline 4 & \multirow{3}{*}{ CAU } & Climate Change is caused by human activity. \\
\hline 5 & & $\begin{array}{l}\text { There is scientific consensus when considering human activity as the main cause } \\
\text { of Climate Change. }\end{array}$ \\
\hline 6 & & Every time coal, oil or gas is used, we contribute to Climate Change. \\
\hline 7 & \multirow{4}{*}{ CSQ } & Climate Change is a consequence of the hole in the ozone layer. \\
\hline 8 & & The $\mathrm{CO}_{2}$ causes the destruction of the ozone layer. \\
\hline 9 & & Climate Change will increase the number of earthquakes and tsunamis. \\
\hline 10 & & The rising temperatures will affect all regions of the planet alike. \\
\hline 11 & \multirow{4}{*}{ A\&M } & The increase in meat consumption contributes to Climate Change. \\
\hline 12 & & If we stop emitting greenhouse gases, we will be less vulnerable to Climate \\
\hline 13 & & The Climate Change would be reduced if we planted more trees. \\
\hline 14 & & $\begin{array}{l}\text { Replacing private transport by the public is one of the most effective measures } \\
\text { to address Climate Change. }\end{array}$ \\
\hline
\end{tabular}


Table A2. Abilities Dimension of Climate Competence. Instructions: Below are a series of statements related to activities you do in your daily life. We ask you to express your degree of agreement or disagreement with each of them.

\begin{tabular}{|c|c|c|}
\hline No. & Dimension & Item \\
\hline 1 & \multirow{3}{*}{ PUR } & $\begin{array}{l}\text { I choose fruits and vegetables produced in my country } \\
\text { over those of foreign origin }\end{array}$ \\
\hline 2 & & I buy local and seasonal products \\
\hline 3 & & I buy organic farming or livestock products \\
\hline 4 & \multirow{3}{*}{ TRA } & I walk or use my bike as a daily means of transportation. \\
\hline 5 & & I use carpooling or public transportation. \\
\hline 6 & & I reduce the use of the car. \\
\hline 7 & \multirow{3}{*}{ ESA } & I consume less electricity \\
\hline 8 & & $\begin{array}{l}\text { I turn off lights and electrical appliances when I am not } \\
\text { using them }\end{array}$ \\
\hline 9 & & I use less heating \\
\hline
\end{tabular}

PUR: Purchases; TRA: Transport, ESA: Energy Savings.

Table A3. Values or Attitudes dimension of Climate Competence. Instructions: Below are a series of statements related to climate change and its inclusion in the educational curriculum. We ask you to express your degree of agreement or disagreement with each of them.

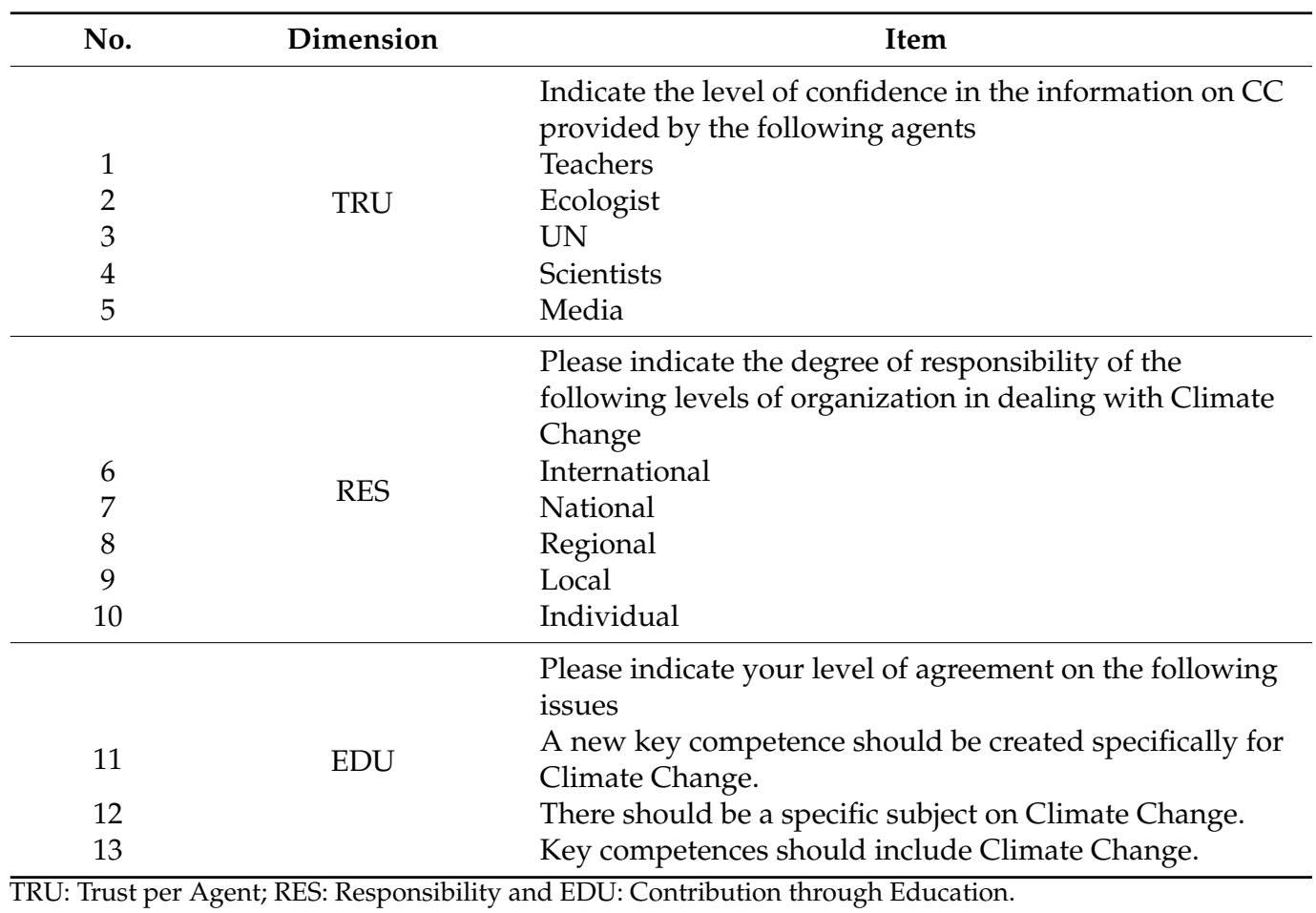

\section{References}

1. IPCC. Climate Change 2014: Impacts, Adaptation, and Vulnerability. Summaries, Frequently Asked Questions, and Cross-Chapter Boxes; A Contribution of Working Group II to the Fifth Assessment Report of the Intergovernmental Panel on Climate Change; IPCC: Geneva, Switzerland, 2014. Available online: https://www.ipcc.ch/site/assets/uploads/2018/03/WGIIAR5 -IntegrationBrochure_FINAL-1.pdf (accessed on 12 December 2020).

2. Zander, K.K.; Mathew, S. Estimating economic losses from perceived heat stress in urban Malaysia. Ecol. Econ. 2019, 159, 84-90. [CrossRef]

3. Anderson, C.; Delisi, M. Implications of Global Climate Change for Violence Developed and Developing Countries. In The Psychology of Social Conflict and Aggression; Forgas, J., Kruglanski, A., Williams, K., Eds.; Psychology Press: New York, NY, USA, 2011; pp. 249-265. 
4. Tawatsupa, B.; Lim, L.L.-Y.; Kjellstrom, T.; Seubsman, S.-A.; Sleigh, A. The Thai Cohort Study Team Association Between Occupational Heat Stress and Kidney Disease Among 37,816 Workers in the Thai Cohort Study (TCS). J. Epidemiol. 2012, 22, 251-260. [CrossRef] [PubMed]

5. Bhattacharya, A. Chapter 1-Global Climate Change and Its Impact on Agriculture. In Changing Climate and Resource Use Efficiency in Plants; Academic Press: Cambridge, MA, USA, 2019; pp. 1-50. [CrossRef]

6. Reeves, M.C.; Bagne, K.E.; Tanaka, J. Potential Climate Change Impacts on Four Biophysical Indicators of Cattle Production from Western US Rangelands. Rangel. Ecol. Manag. 2017, 70, 529-539. [CrossRef]

7. Bybee, R.W. Planet Earth in Crisis: How Should Science Educators Respond? Am. Biol. Teach. 1991, 53, 146-153. [CrossRef]

8. Vilches, A.; Gil-Pérez, D.; Edwards, M.; Praia, J.; Vasconcelos, C. A Actual Crise Planetária: Uma Dimensão Esquecida Na Educação. Rev. Educ. 2004, 12, 59-73.

9. United Nations Development Programme and University of Oxford. Peoples' Climate Vote. 2021. Available online: https: //www.undp.org/content/dam/undp/library/km-qap/UNDP-Oxford-Peoples-Climate-Vote-Results.pdf (accessed on 21 October 2021).

10. IPCC. Special Report on the Ocean and Cryosphere in a Changing Climate (SROCC); IPCC: Geneva, Switzerland, 2019. Available online: https:/ /www.ipcc.ch/2019/ (accessed on 21 August 2021).

11. Buckler, C.; Creech, H. Shaping the Future We Want UN Decade of Education for Sustainable Development (2005-2014). Final Report. 2014. Available online: http://www.unesco.org/open-access/ (accessed on 16 October 2021).

12. United Nations. Resolution Adopted by the General Assembly on 25 September 2015. 2015. Available online: https://www.un. org/en/development/desa/population/migration/generalassembly/docs/globalcompact/A_RES_70_1_E.pdf (accessed on 12 June 2021).

13. United Nations. The Paris Agreement; United Nations: New York, NY, USA, 2016. Available online: https://unfccc.int/sites/ default/files/spanish_paris_agreement.pdf (accessed on 12 June 2021).

14. Mochizuki, Y.; Bryan, A. Climate Change Education in the Context of Education for Sustainable Development: Rationale and Principles. J. Educ. Sustain. Dev. 2015, 9, 4-26. [CrossRef]

15. Stevenson, R.B.; Nicholls, J.; Whitehouse, H. What Is Climate Change Education? Curric. Perspect. 2017, 37, 67-71. [CrossRef]

16. Meira-Cartea, P.A.; Gutiérrez-Pérez, J.; Arto-Blanco, M.; Escoz-Roldán, A. Influence of academic education vs. common culture on the climate literacy of university students/Formación académica frente a cultura común en la alfabetización climática de estudiantes universitarios. PsyEcology 2018, 9, 301-340. [CrossRef]

17. Batchuluun, Y.; Uranchimeg, G. Curriculum Development on Climate Change Adaptation. In Issues in Teaching and Learning of Education for Sustainability; Routledge: London, England, UK, 2019; pp. 85-93. [CrossRef]

18. Chang, C.-H. Liberty Pascua The curriculum of climate change education: A case for Singapore. J. Environ. Educ. 2017, 48, 172-181. [CrossRef]

19. Fahey, S.J. Curriculum change and climate change: Inside outside pressures in higher education. J. Curric. Stud. 2012, 44, 703-722. [CrossRef]

20. Gutiérrez-Pérez, J.; Meira-Cartea, P.A.; González-Gaudiano, E. Educación y comunicación para el cambio climático. Rev. Mex. Investig. Educ. 2020, 87, 819-842.

21. Hess, D.J.; Collins, B.M. Climate change and higher education: Assessing factors that affect curriculum requirements. J. Clean. Prod. 2018, 170, 1451-1458. [CrossRef]

22. Drewes, A.; Henderson, J.; Mouza, C. Professional development design considerations in climate change education: Teacher enactment and student learning. Int. J. Sci. Educ. 2018, 40, 67-89. [CrossRef]

23. Fuertes Prieto, M.Á.; Andrés Sánchez, S.; Corrochano Fernández, D.; Delgado Martín, L.; Herrero Teijón, P.; Ballegeer, A.M.; Ferrari Lagos, E.; Fernández Álvarez, R.; Ruiz Méndez, C. Climate Change Education: A proposal of a Category-Based Tool for Curriculum Analysis to Achieve the Climate Competence. Educ. Knowl. Soc. 2020, 21,1-13.

24. Olsson, D.; Gericke, N.; Sass, W.; Pauw, J.B.-D. Self-perceived action competence for sustainability: The theoretical grounding and empirical validation of a novel research instrument. Environ. Educ. Res. 2020, 26, 742-760. [CrossRef]

25. Gericke, N.; Pauw, J.B.-D.; Berglund, T.; Olsson, D. The Sustainability Consciousness Questionnaire: The theoretical development and empirical validation of an evaluation instrument for stakeholders working with sustainable development. Sustain. Dev. 2019, 27, 35-49. [CrossRef]

26. Montero-Pau, J.; Álvaro, N.; Gavidia, V.; Mayoral, O. Development of Environmental Health Competencies through Compulsory Education. A Polyhedral Approach Based on the SDGs. Sustainability 2020, 12, 3215. [CrossRef]

27. Pedersen, D.M. Dimensions of environmental competence. J. Environ. Psychol. 1999, 19, 303-308. [CrossRef]

28. Karami, S.; Shobeiri, S.M.; Jafari, H. Assessment of knowledge, attitudes, and practices (KAP) towards climate change education (CCE) among lower secondary teachers in Tehran, Iran. Int. J. Clim. Chang. Strateg. Manag. 2017, 9, 402-415. [CrossRef]

29. Van Basshuysen, P.; Brandstedt, E. Comment on 'The climate mitigation gap: Education and government recommendations miss the most effective individual actions'. Environ. Res. Lett. 2018, 13, 048001. [CrossRef]

30. Ekborg, M.; Areskoug, M. How student teachers' understanding of the greenhouse effect develops during a teacher education programme. Nord. Stud. Sci. Educ. 2012, 2, 17. [CrossRef]

31. Boyes, E.; Stanisstreet, M. Environmental Education for Behaviour Change: Which actions should be targeted? Int. J. Sci. Educ. 2012, 34, 1591-1614. [CrossRef] 
32. Goldman, D.; Yavetz, B.; Pe'Er, S. Environmental Literacy in Teacher Training in Israel: Environmental Behavior of New Students. J. Environ. Educ. 2006, 38, 3-22. [CrossRef]

33. Otto, S.; Neaman, A.; Richards, B.; Marió, A. Explaining the Ambiguous Relations Between Income, Environmental Knowledge, and Environmentally Significant Behavior. Soc. Nat. Resour. 2016, 29, 628-632. [CrossRef]

34. Bradley, J.C.; Waliczek, T.M.; Zajicek, J.M. Relationship Between Environmental Knowledge and Environmental Attitude of High School Students. J. Environ. Educ. 1999, 30, 17-21. [CrossRef]

35. Kerstin, L.; Ahlström, R.; Jan, L.; Jari, L. Values, attitudes, moral judgment competence, locus of control and sense of coherence as de-terminants of proenvironmental behaviors and behavioral intentions. J. Multidiscip. Eng. Sci. Technol. JMEST 2017, 4, 2568-2583.

36. Meinhold, J.L.; Malkus, A.J. Adolescent environmental behaviors: Can knowledge, attitudes and self-efficacy make a difference? Environ. Behav. 2005, 37, 511-532. [CrossRef]

37. Tasquier, G.; Pongiglione, F. The influence of causal knowledge on the willingness to change attitude towards climate change: Results from an empirical study. Int. J. Sci. Educ. 2017, 39, 1846-1868. [CrossRef]

38. Ferrari-Lagos, E.; Martínez-Abad, F.; Ruíz, C. The Importance of Motivation and Communication in MOOCs as Elements to Increase Completion Rates: A Study at MOOCs on Climate Change. In Proceedings of the Eighth International Conference on Technological Ecosystems for Enhancing Multiculturality, Salamanca, Spain, 21-23 October 2020; Association for Computing Machinery: New York, NY, USA, 2020; pp. 1042-1047. [CrossRef]

39. Mcdonald, R.P. Test Theory. A Unified Treatment; Lawrence Erlbaum Associates Inc.: Mahwah, NJ, USA, 1999.

40. Gadermann, A.M.; Guhn, M.; Zumbo, B.D. Estimating ordinal reliability for likert-type and ordinal item response data: A conceptual, empirical, and practical guide. Pract. Assess. Res. Eval. 2012, 17, 1-13.

41. USGCRP. The Essential Principles of Climate Literacy. 2009. Available online: https://bit.ly/33NwvrE (accessed on 12 August 2021).

42. Nyarko, S.C.; Petcovic, H.L. Ghanaian preservice science teachers' knowledge of ozone depletion and climate change, and sources of their knowledge. Int. J. Sci. Educ. 2021, 43, 1554-1575. [CrossRef]

43. García-Vinuesa, A.; Meira Cartea, P.; Arto Blanco, M.; Bisquert, K. Social representations of climate change in a group of college students from the University of Santiago de Compostela: Common culture vs. scientific culture. Eco Think. 2019, 1.

44. Seroussi, D.-E.; Rothschild, N.; Kurzbaum, E.; Yaffe, Y.; Hemo, T. Teachers' Knowledge, Beliefs, and Attitudes about Climate Change. Int. Educ. Stud. 2019, 12, 8. [CrossRef]

45. Schreiber, J.B.; Nora, A.; Stage, F.K.; Barlow, E.A.; King, J. Reporting Structural Equation Modeling and Confirmatory Factor Analysis Results: A Review. J. Educ. Res. 2006, 99, 323-338. [CrossRef]

46. Bain, P.G.; Milfont, T.L.; Kashima, Y.; Bilewicz, M.; Doron, G.; Gardarsdottir, R.B.; Gouveia, V.V.; Guan, Y.; Johansson, L.-O.; Pasquali, C.; et al. Co-benefits of addressing climate change can motivate action around the world. Nat. Clim. Change 2016, 6, 154-157. [CrossRef]

47. Gifford, R.; Comeau, L.A. Message framing influences perceived climate change competence, engagement, and behavioral intentions. Glob. Environ. Change 2011, 21, 1301-1307. [CrossRef]

48. Whitmarsh, L.; O'Neill, S. Green identity, green living? The role of pro-environmental self-identity in determining consistency across diverse pro-environmental behaviours. J. Environ. Psychol. 2010, 30, 305-314. [CrossRef]

49. Boon, H. Teachers and the Communication of Climate Change Science: A Critical Partnership in Australia. Procedia-Soc. Behav. Sci. 2014, 116, 1006-1010. [CrossRef]

50. Fuertes, M.; Andrés-Sánchez, S.; Corrochano, D.; Delgado, L.; Herrero-Teijón, P.; Ballegeer, A.-M.; Ferrari, E.; Ruiz, C. Development of Teacher's Climate Change Competence Through MOOCs and Other Online Courses. In Proceedings of the 15th International Technology, Education and Development Conference, Online, 8-9 March 2021; pp. 525-532. [CrossRef]

51. IPCC. Climate Change 2014: Mitigation of Climate Change; Contribution of Working Group III to the Fifth Assessment Report of the Intergovernmental Panel on Climate Change; Cambridge University Press: Cambridge, UK; New York, NY, USA, 2014.

52. Meira, P.A.; Arto, M.; Iglesias da Cunha, L.; Lorenzo-Castiñeras, J.J.; Montero-Souto, P. La Respuesta de la Sociedad Española ante el Cambio Climático. 2013. Available online: http:/ / cambioclimatico.gob.mx:8080/xmlui/handle/publicaciones/327 (accessed on 12 September 2020).

53. Gowda, M.V.R.; Fox, J.C.; Magelky, R.D. Students' Understanding of Climate Change: Insights for Scientists and Educators. Bull. Am. Meteorol. Soc. 1997, 78, 2232-2240. [CrossRef]

54. Andrés, J.M. La Investigación ex Post-Facto; La Muralla: Madrid, Spain, 2004; pp. 196-230.

55. Kerlinger, F.N.; Lee, H.B.; Esther, L.; Mora Magaña, I. Foundations of Behavioral Research, 4th ed.; McGraw-Hill: New York, NY, USA, 2002.

56. Cohen, J. Statistical Power Analysis for the Behavioral Sciences, 2nd ed.; Lawrence Earlbaum Associates: Hillsdale, MI, USA, 1988.

57. Preacher, K.J.; Kelley, K. Effect size measures for mediation models: Quantitative strategies for communicating indirect effects. Psychol. Methods 2011, 16, 93-115. [CrossRef]

58. Ferrari-Lagos, E.; Martínez-Abad, F.; Ruíz, C. Education to Mobilize Society for Climate Change Action: The Climate Competence in Education. In Proceedings of the the Seventh International Conference on Technological Ecosystems for Enhancing Multiculturality, Leon, Spain, 16-18 October 2019; Association for Computing Machinery: New York, NY, USA, 2019; pp. 966-970. [CrossRef] 
59. Salas-Zapata, W.; Cardona-Arias, J.A. Knowledge, attitudes and practices of sustainability in two university populations, Colombia. J. Appl. Res. High. Educ. 2020, 13, 914-924. [CrossRef]

60. Masud, M.M.; Akhtar, R.; Afroz, R.; Al-Amin, A.Q.; Kari, F.B. Pro-environmental behavior and public understanding of climate change. Mitig. Adapt. Strat. Glob. Change 2015, 20, 591-600. [CrossRef]

61. Liu, P.; Teng, M.; Han, C. How does environmental knowledge translate into pro-environmental behaviors?: The mediating role of environmental attitudes and behavioral intentions. Sci. Total Environ. 2020, 728, 138126. [CrossRef] [PubMed]

62. Polonsky, M.J.; Vocino, A.; Grau, S.L.; Garma, R.; Ferdous, A.S. The impact of general and carbon-related environmental knowledge on attitudes and behaviour of US consumers. J. Mark. Manag. 2012, 28, 238-263. [CrossRef]

63. Zhang, W.; Xu, R.; Jiang, Y.; Zhang, W. How Environmental Knowledge Management Promotes Employee Green Behavior: An Empirical Study. Int. J. Environ. Res. Public Health 2021, 18, 4738. [CrossRef] [PubMed]

64. Waris, I.; Hameed, I. Promoting environmentally sustainable consumption behavior: An empirical evaluation of purchase intention of energy-efficient appliances. Energy Effic. 2020, 13, 1653-1664. [CrossRef]

65. Busch, K. Textbooks of doubt, tested: The effect of a denialist framing on adolescents' certainty about climate change. Environ. Educ. Res. 2021, 27, 1574-1598. [CrossRef]

66. Levine, D.S.; Strube, M.J. Environmental Attitudes, Knowledge, Intentions and Behaviors Among College Students. J. Soc. Psychol. 2012, 152, 308-326. [CrossRef]

67. Kuhlemeier, H.; Bergh, H.V.D.; Lagerweij, N. Environmental Knowledge, Attitudes, and Behavior in Dutch Secondary Education. J. Environ. Educ. 1999, 30, 4-14. [CrossRef]

68. Higde, E.; Oztekin, C.; Sahin, E. Turkish pre-service science teachers' awareness, beliefs, values, and behaviours pertinent to climate change. Int. Res. Geogr. Environ. Educ. 2017, 26, 253-263. [CrossRef]

69. Gan, Y.; Xu, T.; Xu, N.; Xu, J.; Qiao, D. How Environmental Awareness and Knowledge Affect Urban Residents' Willingness to Participate in Rubber Plantation Ecological Restoration Programs: Evidence from Hainan, China. Sustainability 2021, $13,1852$. [CrossRef]

70. Hamzah, M.I.; Tanwir, N.S. Do pro-environmental factors lead to purchase intention of hybrid vehicles? The moderating effects of environmental knowledge. J. Clean. Prod. 2020, 279, 123643. [CrossRef]

71. Maumoh, I.; Yindi, E.H. Understanding the Farmers' Environmental Citizenship Behaviors Towards Climate Change: The Moderating Mediating Role of Environmental Knowledge and Ascribed Responsibility. Int. J. Adv. Eng. Manag. Sci. 2021, 7, 09-22. [CrossRef]

72. Tamar, M.; Wirawan, H.; Arfah, T.; Putri, R.P.S. Predicting pro-environmental behaviours: The role of environmental values, attitudes and knowledge. Manag. Environ. Qual. Int. J. 2020, 32, 328-343. [CrossRef]

73. Kautish, P.; Paul, J.; Sharma, R. The moderating influence of environmental consciousness and recycling intentions on green purchase behavior. J. Clean. Prod. 2019, 228, 1425-1436. [CrossRef] 